\title{
Caso de hipertermia maligna en paciente intervenida de apendicectomía laparoscópica
}

\author{
Malignant Hyperthermia after a laparoscopic \\ appendicectomy: Case report
}

Ángela Leonor Ruiz García¹, Laura María Alcázar Sánchez-Elvira', Rocío Molina Montero', Clara Serrano Ferrer ${ }^{1}$

\begin{abstract}
Malignant hyperthermia is an hypermetabolic syndrome in which the intracellular calcium receptors are altered. Patients who present compatible symptoms with this symdrome are genetically predisposed. Many of the cases have been described in the surgical area, due to the use of anesthesic drugs and neuromuscular blockers. However, there are some cases with an unknown trigger. The prevalence of the syndrome is very difficult to estimate. The diagnosis and early treatment are pronostic factors predicting the evolution of the syndrome.
\end{abstract}

\section{RESUMEN}

La hipertermia maligna es conocida como un síndrome de estimulación masiva del metabolismo, debido a la alteración en la liberación de calcio intracelular. Muchos pacientes que presentan clínica compatible con este síndrome están genéticamente predispuestos. La mayoría de los casos se describen en el ámbito quirúrgico, con el empleo de fármacos anestésicos y determinados relajantes neuromusculares, aunque también existen casos en los que no se halla desencadenante. De prevalencia difícil de estimar, la sospecha diagnóstica y el tratamiento precoz marcan el pronóstico evolutivo de estos pacientes.

\section{Key words:}

Dantrolene, muscle relaxants, inhalatory anesthesia, malignant hyperthermia

\section{Palabras clave:}

Dantroleno,

bloqueantes

neuromusculares,

anestésicos

halogenados,

hipertermia maligna

Cuidado Intensivo, Hospital Universitario Príncipe de Asturias.

Fecha de recepción: 16 de junio de 2020

Fecha de aceptación: 22 de octubre de 2020

\section{ORCID}

0000-0001-9631-8088

\section{Correspondencia:}

Ángela Ruiz García

aruiz.22@alumni.unav.es 


\section{Introducción}

$\mathrm{E}$ síndrome de hipertermia maligna se define como un estado hipermetabólico desencadenado en la mayoría de los casos tras exposición farmacológica en pacientes genéticamente susceptibles. Se han descrito casos desarrollados de manera espontánea, sin exposición o causa conocida[1].

Fármacos descritos como desencadenantes de este síndrome son los relajantes neuromusculares despolarizantes tipo succinilcolina o los gases halogenados como el sevofluorano. Los antagonistas de los canales de calcio también se relacionan como posibles desencadenantes de hipertermia maligna[2].

En los casos con mediación genética, se han identificado numerosas mutaciones que afectan en su mayoría a genes del receptor del músculo esquelético. Estas alteraciones producen un acúmulo excesivo de calcio intracelular, alterando la contracción muscular.

Un gran número de estas mutaciones son de herencia autosómica dominante de penetrancia incompleta y expresividad muy variable. El resto, son mutaciones de novo.

Por todo ello, el modo de presentación y la clínica de este síndrome suele ser muy heterogéneo, dificultando el poder estimar la prevalencia en la población general, siendo muy variable según las series[3] (Tabla 1).

Se describe el caso de una mujer de 54 años, natural de Colombia, con antecedentes médicos personales de espondiloartrosis y enfermedad de Suddeck. No presenta factores de riesgo cardiovascular ni hábitos tóxicos. No alergias medicamentosas.

Intervenida quirúrgicamente de síndrome de túnel del carpo bilateral y una cesárea realizada en su país.

Recibe tratamiento habitual con sertralina, arcoxia, tramadol/Paracetamol; gabapentina, trazodona y omeprazol.
La paciente acude a servicio urgencias por un cuadro de dolor abdominal en fosa ilíaca derecha de $12 \mathrm{~h}$ de evolución de intensidad moderada-severa, acompañado de fiebre de hasta $38^{\circ} \mathrm{C}$ junto con náuseas y vómitos de contenido alimenticio. No deposiciones diarreicas, ni productos patológicos en las mismas.

No refiere cuadro compatible con infección de origen respiratorio, sin clínica relacionada con infección por COVID-19. No contactos epidemiológicos de riesgo.

A la exploración la paciente presenta aceptable estado general, normocoloreada y bien perfundida. Saturación basal 96\%, tensión arterial 124/72 mmHg; frecuencia cardíaca $100 \mathrm{lpm}$, temperatura axilar $36^{\circ}$ C. Abdomen blando aunque doloroso a la palpación en fosa ilíaca derecha, Murphy negativo, Blumberg dudoso, sin palpación de masas ni megalias.

Se solicitan pruebas de laboratorio en las que se objetiva leucocitosis de $14.500 /$ ucl sin neutrofilia, con cifras de hemoglobina y plaquetas sin alteraciones. Parámetros de coagulación normales. PCR en ascenso de 55,5 mg/l, sin alteración de la función renal o del ionograma. PCR de exudado nasofaríngeo y serologías de COVID-19 negativas.

Ante estos hallazgos, se solicita valoración por Servicio Cirugía General, quienes consideran oportuna la realización de una prueba de imagen. En la ecografía abdominal se identifica en fosa ilíaca derecha una estructura tubular, que se origina en el ciego y termina en fondo de saco, aperistáltica, con morfología en capas y compatible con el apéndice cecal con un calibre máximo de $12 \mathrm{~mm}$ que asocia trabeculación de la grasa locorregional, con mínima lengüeta de líquido libre perilesional. Blumberg ecográfico positivo. Dichos hallazgos son compatibles con apendicitis aguda.

Una vez obtenido el diagnóstico, se comenta con la paciente la necesidad de someterla a intervención quirúrgica. Se explican riesgos, que la paciente en-

\begin{tabular}{ll} 
& Tabla 1. \\
\hline Prevulencia & $\mathbf{1 : 2 . 0 0 0 - 1 : 3 . 0 0 0}$ \\
Predisposición genética & Autosómica dominante \\
& De novo \\
Mutación & Genes de control de calcio del retículo sarcoplásmico \\
Genes alterados & RYR1, DHP, STAC3 \\
Causas & Exposición farmacológica: \\
& - Bloqueantes neuromusculares despolarizantes: succinilcolina \\
& - Anestésicos halogenados: Sevofluorano \\
& - Antagonistas del calcio \\
& No desencadenante \\
Idiopático
\end{tabular}


tiende, firmando consentimiento informado.

Se procede a inducción anestésica con 200 mg de propofol, $20 \mathrm{mcg}$ de fentanilo y $60 \mathrm{mg}$ de rocuronio, realizando intubación orotraqueal sin incidencias.

Se comienza anestesia de mantenimiento con Desflurano como gas halogenado, momento en el cual se observa discreto aumento de la frecuencia cardíaca. En los siguientes minutos presenta elevación progresiva de $\mathrm{EtCO}_{2}$ hasta 60 , que mantiene a pesar de ventilación con volúmenes minuto elevados. Taquicardia sinusal en torno a $140 \mathrm{lpm}$, con tendencia a la hipertensión. Temperatura axilar $37,8^{\circ} \mathrm{C}$.

Se solicita valoración por Servicio Cardiología quien realiza ecocardiografía portátil en el que el ventrículo izquierdo no está dilatado, con paredes de grosor normal, FEVI 60\%, sin alteraciones de la contractilidad. Ventrículo derecho de tamaño normal normofuncionante. Aurículas de tamaño normal. No se observan valvulopatías ni presencia de shunt. Raíz aórtica no dilatada.

Ante la persistencia de taquicardia sinusal y la EtCO $\mathrm{O}_{2}$ en ascenso, se decide colocación de sonda esofágica para medición de temperatura central, objetivando cifra de $40,3{ }^{\circ} \mathrm{C}$. Se extrae gasometría arterial de control en la que se objetiva acidosis metabólica con un $\mathrm{pH} 7,24$ y $\mathrm{HCO} 3$ 18,3, sin hipercapnia $\left(\mathrm{pCO}_{2}\right.$ 43,9).

Dada la situación clínica y signos y hallazgos observados, se sospecha un síndrome de hipertermia maligna secundaria a anestesia con desflorano y se decide suspender la intervención quirúrgica.

Se modifica pauta de sedoanalgesia, empleando perfusiones continuas de propofol y remifentanilo (fármacos seguros en la hipertermia maligna), se suspende gas anestésico y se inician medidas físicas para enfriamiento (manta térmica), además de sueroterapia fría.

Se canaliza vía venosa central y arteria radial para monitorización invasiva.

Se inicia dantroleno intravenoso a dosis de 2,5 $\mathrm{mg} / \mathrm{kg}$, administración única durante 15 minutos, observándose disminución de la frecuencia cardíaca progresiva y descenso de la temperatura central de la paciente hasta $37,5^{\circ} \mathrm{C}$.

Ingresa en la unidad de cuidados intensivos, sedoanalgesiada con propofol y remifentanilo, manteniendo RASS $-4,-5$, adecuadamente adaptada al respirador.

Requerimientos de soporte respiratorio, mantenemos en ventilación mecánica con volúmenes minuto elevados y $\mathrm{FiO}_{2}$ 100\%, para fomentar la hiperventilación.

Mejoría evolutiva con recuperación de frecuencia

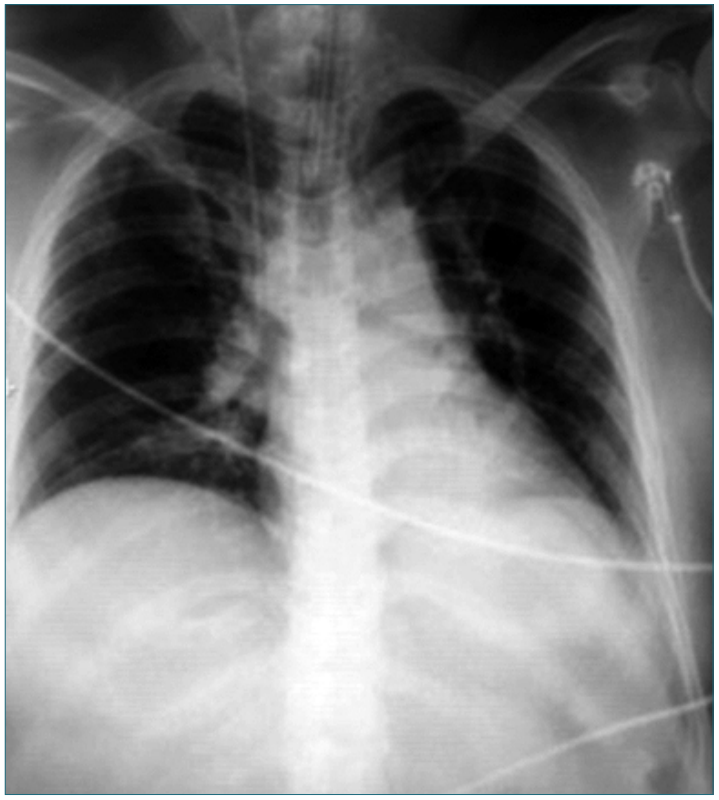

Figura 1. Radiografía de tórax al ingreso en UCI.

cardíaca, manteniendo en ritmo sinusal a 85 lpm, con tensión arterial sistólica en torno a $90 \mathrm{mmHg}$, por lo que se decide iniciar soporte vasoactivo con noradrenalina a dosis de $0,1 \mathrm{mcg} / \mathrm{kg} / \mathrm{min}$, con lo que mantiene tensiones medias adecuadas.

Dado el cuadro de apendicitis aguda no intervenida y consensuado con el equipo de cirugía se decide iniciar cobertura de antibiótico con amoxicilina-clavulánico (Figura 1).

En la analítica de ingreso, no se observa leucocitosis ni neutrofilia, plaquetas en rango y hemoglobina de 10,6 g/dl. No se observan alteraciones de la coagulación.

Función renal conservada con hipopotasemia de 3,1 mmol/l. CK $30 \mathrm{U} / \mathrm{l}$ sin elevación de LDH. Reactantes de fase aguda en discreto aumento con PCT 1,42 $\mathrm{ng} / \mathrm{ml}$ y PCR 72,3 mg/l. En gasometría, acidosis mixta con $\mathrm{HCO} 318,7$ y $\mathrm{pCO}_{2} 30$, con lactato elevado de 3,7 $\mathrm{mmol} / \mathrm{l}$. Se ajustan parámetros del respirador.

En el día +1 de ingreso, se realiza ventana de sedación para evaluar estado neurológico de la paciente, observándose adecuada respuesta a estímulos y órdenes, con movilización de las cuatro extremidades.

En analítica de control, elevación de cifras leucocitarias con neutrofilia acompañante, sin coagulopatía ni plaquetopenia. Llamativo aumento de cifras de PCT $36,96 \mathrm{ng} / \mathrm{ml}$ y PCR $141,8 \mathrm{mg} / \mathrm{l}$, manteniendo acidosis mixta con lactato en descenso de $2,5 \mathrm{mmol} / \mathrm{l}$. 
A la exploración, el abdomen sigue siendo blando, aunque doloroso a la palpación sobre todo en fosa ilíaca derecha.

Se comenta caso de manera interdisciplinar con los servicios de anestesia y cirugía general, decidiendo intervención quirúrgica mientras permanezca en condiciones de sedoanalgesia e intubación orotraqueal.

Se comenta con familiares de la paciente las ventajas e inconvenientes, decidiendo finalmente autorizar intervención, firmando consentimiento informado.

Se realiza apendicectomía por laparoscopia sin complicaciones y regresa de nuevo a la $\mathrm{UCl}$, para vigilancia estrecha, rotando antibioterapia a piperacilina-tazobactam, por aumento de reactantes de fase aguda, con un láctico $1 \mathrm{mmol} / \mathrm{l}$ y PCR de 188,4 mg/l y hallazgo intraoperatorio de líquido periapendicular turbio.

Muy buena evolución posterior, manteniéndose afebril y hemodinámicamente estable, pudiendo ser extubada el día +2 de ingreso en $\mathrm{UCl}$ con retirada de soporte vasoactivo.

Disminución de progresiva de leucocitos y reactantes de fase aguda, sin fallo de órganos acompañantes, pudiendo iniciar tolerancia oral sin complicaciones.

Dada la buena evolución clínica, se decide alta a planta de Cirugía para continuar vigilancia y tratamiento.

\section{Referencias}

1. Gupta PK, Hopkins PM. Diagnosis and management of malignant hyperthermia. BJA Educ 2017;17(7):249-54. https://doi. org/10.1093/bjaed/mkw079.
2. Kollmann-Camaiora A, Alsina E, Domínguez A, Del Blanco B, Yepes MJ, Guerrero JL, et al. Protocolo clínico asistencial de manejo de la hipertermia maligna. Rev Esp Anestesiol Reanim. 2017 Jan;64(1):32-40. https://doi.org/10.1016/j. redar.2016.06.004 PMID:27633384

3. Marino PL. Trastornos de la temperatura corporal. El libro de la UCl. 4th. New York: Wolters Kluwer; 2015. pp. 761-75. 